\title{
HLA-D and -DR Antigens in Genetic Analysis of Insulin Dependent Diabetes Mellitus
}

\author{
P. Platz ${ }^{1}$, B. K. Jakobsen ${ }^{1}$, N. Morling ${ }^{1}$, L. P. Ryder ${ }^{1}$, A. Svejgaard ${ }^{1}$, M. Thomsen ${ }^{1}$, M. Christy ${ }^{2}$, H. Kromann ${ }^{2}$, \\ J. Benn ${ }^{2}$, J. Nerup ${ }^{2}$, A. Green ${ }^{3}$ and M. Hauge ${ }^{3}$ \\ ${ }^{1}$ Tissue Typing Laboratory of the Blood Grouping Department, University Hospital (Rigshospitalet), Copenhagen, \\ and ${ }^{2}$ Steno Memorial Hospital, Gentofte, and ${ }^{3}$ Institute of Clinical Genetics, University of Odense, Denmark
}

\begin{abstract}
Summary. Three groups of patients with insulindependent diabetes mellitus, ascertained by different procedures, were investigated for HLA-A, B, C and $D$ antigens $(n=164)$, and a subset $(n=93)$ for HLA-DR. Both HLA-D/DR3 and D/DR4 were strongly positively associated and D/DR2 was negatively associated with insulin-dependent diabetes. HLA-DR4 was found to be a better marker for insulin-dependent diabetes than Dw4. The HLA-B associations (B8, B15 and B18) were clearly secondary to the increases of HLA-D/DR3 and D/DR 4. The HLA associations did not differ between familial and isolated cases indicating that these two groups may well have a common genetic background. Based on analysis of HLA-haplotype sharing in affected sibling pairs, a simple dominant model of inheritance could be ruled out, and a simple recessive model was found unlikely. The relative risks for the HLADw3,4 and HLA-DR3,4 phenotype were 21.2 and 44.4 respectively and exceeded those of both the HLA-Dw3 and HLA-DR3 (5.6 and 4.3) as well as the HLA-Dw4 and DR4 (10.1 and 10.5) phenotypes. This argues against an intermediate genetic model but further studies are needed to clarify whether there is more than one susceptibility gene for insulin-dependent diabetes mellitus within the HLA-system.
\end{abstract}

Key-words: HLA, genetics, heterogeneity of insulindependent diabetes.

In 1974 we confirmed and extended [20] the observations by Singal and Blajchman [26] that insulindependent diabetes mellitus (IDD) but not non-insulin-dependent diabetes mellitus (NIDD) is associated with certain HLA factors. Several studies have substantiated these observations and results of studies of more than 1500 Caucasian IDD patients have now been reported $[5,7,23]$. The HLA system is the major histocompatibility complex of man and is controlled by closely linked genes located on the short arm of chromosome 6 . The system has recently been extensively reviewed $[11,12,31]$.

Association between IDD and HLA factors has also been found in other ethnic groups [32], but so far the association has been most extensively studied in Caucasians and this report deals only with this group.

Since our first report [20], we have continued HLA studies in IDD with the ultimate goal of constructing a genetic model for IDD which could fit the genetic information obtained by HLA studies as well as the independent results from epidemiological and familial studies.

The specific problems we have tried to solve may be categorized as follows: (a) which HLA factors show the strongest association with IDD [35], i.e. what can be deduced about the location of genes conferring susceptibility to develop IDD in relation to the known loci of the HLA system; (b) are there differences in the HLA profile between familial and isolated cases of IDD [30, 36], i.e. are there genes with major effect on IDD located outside the HLA region? (c) does genetic heterogeneity exist within HLA-associated IDD [21,30], does HLA determine susceptibility by more than one mechanism, and is it possible by HLA typing to distinguish between certain clinical subtypes of IDD? (d) what is the proportion of shared HLA haplotypes in affected sibling pairs with IDD [24], i. e. can specific modes of inheritance of IDD suspectibility genes in the HLA region be rendered (un)likely by sibling studies?

We have now reanalyzed some of our previous data together with a new and unpublished series in 
the light of our growing experience with the errors and pitfalls of ascertainment, HLA typing and statistical analysis in this type of research.

\section{Materials and Methods}

\section{Patient Groups}

All patients included in this report were insulin-dependent diabetics according to the criteria proposed by the National Diabetes Data Group [19]. Three groups of patients with IDD have been studied:

1) A prospective study of all new cases of IDD in Caucasoids in the metropolitan area of Copenhagen, Denmark. This area, including the City of Copenhagen, Frederiksborg municipality and the counties of Copenhagen and Frederiksborg, is inhabited by approximately 1.5 million people, almost exclusively Caucasoids of Scandinavian ancestry. The patients were ascertained on admission to paediatric or medical wards in the area by members of our study group. Eighty-seven patients with onset of IDD before age 30 years were identified between 1 May 1975 and 1 June 1976. The number of patients ascertained in the prospective study did not differ significantly from the average number of patients ascertained during a similar period in the preceding 5 years [4] suggesting that ascertainment was almost complete. From this group of 87 patients blood for HI.A-A, B, C typing was obtained from 79 patients; 73 of these were HLA-D typed and 27 HLA-DR typed. There was no evidence that the patients who were not HLA typed in this group differed from the others in terms of age at onset.

2) Pairs of siblings both suffering from IDD were identified from the case records of the Steno Memorial Hospital, Gentofte, Denmark, which provides diabetes care to patients from all over Denmark, though predominantly from the metropolitan area of Copenhagen. The 31 pairs living nearest to Copenhagen were investigated for HLA-A,B,C and D antigens. No age limits were used for this group and the older sibling in each family was considered proband.

3) In the Funen region of Denmark, which has approximately 450,000 inhabitants ( $9 \%$ of Danish population), the total population of insulin treated diabetics on 1 July 1973 was recorded in a prevalence study [10]. A mailed questionnaire was sent to all those born between 1 July 1943 and 30 June 1958, with onset of IDD below age 20 years $(n=223)$. Clinical data were obtained from the patients and from hospital records to confirm insulin dependence. From this group, all families with two or more affected siblings and with living parents were registered, and blood samples from the affected siblings and their parents were collected for typing ( 20 available families). In addition, 46 diabetics from the group with at least two healthy siblings aged 20 years or more and without affected first degree relatives were randomly selected for blood sampling. All 126 individuals were investigated for HLAA,B,C and -DR antigens with the 8th Histocompatibility Workshop typing set. Sixty-two of these probands were also typed for HLA-D. Typing for HLA-D/DR associated Primed Lymphocyte Typing (PLT) defined "DP"-antigens was performed in 12 of these patients when discrepancies between HLA-D and -DR typing were found and when frozen lymphocytes were available.

In the following analyses the three different patient groups will be designated: (1) the prospective series, (2) the sibling pair series and (3) the Funen series. None of the individuals were ascertained in both the prospective and the Funen series. Three siblings from the sibling pair series were also found in the prospective series. These probands were assigned to the prospective series and the three pairs were used for analysis of sharing of haplotypes. One sibling pair was found in both the sibling pair and the Funen series and the proband was assigned to the Funen series. In each of six kindreds containing three affected siblings, only the two eldest siblings were included in the analysis. Altogether 173 unrelated probands were analyzed in the three series. Table 1 presents the three groups in terms of method of ascertainment, number of patients, sex, age at onset, time of diagnosis and HLA analysis performed.

\section{Control Subjects}

The control material comprises 338 unrelated blood donors or hospital staff members, all typed for HLA-A,B and C antigens. More than 300 were typed for HLA-D (Table 5), and 260 were typed for HLA-DR. One hundred and thirteen were typed for both HLA-D and -DR antigens.

\section{HLA-Typing Methods}

HLA-A,B,C typing was performed on freshly isolated lymphocytes from defibrinated blood. Blood for HLA-D and -DR typing was drawn into equal amounts of RPMI 1640 (Gibco, Glasgow), lymphocytes were isolated by gradient flotation on Lymphoprep (Nyegaard, Oslo), frozen with DMSO in a controlled freezing system (Cryoson) and stored in liquid nitrogen until later investigations.

HLA-A,B,C typing was performed with the KissmeyerNielsen technique as previously described [14]. HLA-D typing was done with local typing cells covering the following specificities: HLA-Dw1 to 8 and the local specificity $D^{\text {" }} \mathrm{H}^{\prime}$ " as described by Thomsen et al. [33, 34].

HLA-DR typing for HLA-DR1,2,3,4,7 and w8 was performed for 27 patients from the prospective groups with sera and technique from the 7 th Histocompatibility Workshop [11] and for all individuals from the Funen series with the 'orange' serum set and technique in the 8th Histocompatibility Workshop [12] covering the specifities HLA-DR1,2,3,4,5,7 and w8. HLA-DRw6 could not be meaningfully assigned in any of these series.

Typing for HLA-D/DR associated "DP"-antigens defined by the Primed Lymphocyte Typing (PLT) technique was performed as described by Morling et al. [16]. The PLT-cells were generated by priming selected responder cells with the homozygous typing cells used for HLA-D typing. DP-typing was performed for the alloantigens DP1 to 8 and DP"H", which are strongly associated with the antigens HLA-D/DR1 to w8 and D"H" [17].

\section{Statistical Methods}

The probability (p) values quoted were obtained by Fisher's exact test (uncorrected for the number of specificities tested for). The relative risks were calculated by Woolf's method [31]. Investigation for Hardy-Weinberg equilibrium [3] was done by the gene counting method of maximum likelihood. The analysis of the distribution of HLA haplotype sharing among affected sibling pairs was based on the method of Day and Simons [8] as modified by Thomson and Bodmer [37].

\section{Results}

\section{Is the Association Closest with HLA-B or -D/DR?}

The HLA-B antigens B8, B15 and B18, and HLA$D / D R$ antigens D/DR3 and D/DR4, were increased in all the groups of propositi with IDD. In order to test whether the HLA-B or the D/DR antigens 
Table 1. Clinical data in different patient groups

\begin{tabular}{|c|c|c|c|}
\hline Group characteristics & Prospective series & Sibling pair series & Funen series \\
\hline Method of ascertainment & $\begin{array}{l}\text { All new cases of IDD in the met- } \\
\text { ropolitan area of Copenhagen }\end{array}$ & $\begin{array}{l}\text { From case records at the Steno } \\
\text { Memorial Hospital }\end{array}$ & $\begin{array}{l}\text { Prevalence population of IDD } \\
\text { patients on the Island of Funen, } \\
1 \text { July } 1973\end{array}$ \\
\hline Time of diagnosis of IDD & 1 May 1975 to 31 May 1976 & $\begin{array}{l}\text { One in } 1922 \text {, the rest from } 1949 \\
\text { to } 1978\end{array}$ & $\begin{array}{l}\text { Probands born from July } 1943 \text { to } \\
\text { June } 1958\end{array}$ \\
\hline $\begin{array}{l}\text { Number of probands } \\
\text { Male/female }\end{array}$ & $\begin{array}{l}79 \\
48 / 31\end{array}$ & $\begin{array}{l}28 \\
13 / 15\end{array}$ & $\begin{array}{l}66 \\
34 / 32\end{array}$ \\
\hline $\begin{array}{l}\text { Age at onset (years): } \\
\text { Range } \\
\text { Median }\end{array}$ & $\begin{array}{l}0-29 \\
14\end{array}$ & $\begin{array}{l}2-61 \\
21\end{array}$ & $12^{1-20}$ \\
\hline $\begin{array}{l}\text { Number of probands type } \\
\text { HLA-A,B,C } \\
\text { HLA-D } \\
\text { HLA-DR }\end{array}$ & $\begin{array}{l}79 \\
73 \\
27 \text { (7th Workshop) }\end{array}$ & $\begin{array}{l}28 \\
28 \\
\text { n.i. }\end{array}$ & $\begin{array}{l}66 \\
62 \\
66 \text { (8th Workshop) }\end{array}$ \\
\hline
\end{tabular}

n.i. $=$ not investigated

Table 2. HLA-B, D, and -DR associations in selected phenotypic groups of patients and controls: detection of the strongest association

\begin{tabular}{|c|c|c|c|c|c|c|c|}
\hline \multirow{2}{*}{$\begin{array}{l}\text { Group used } \\
\text { for comparison }\end{array}$} & \multirow{2}{*}{$\begin{array}{l}\text { Antigen } \\
\text { compared }\end{array}$} & \multicolumn{2}{|c|}{ Number of } & \multicolumn{2}{|c|}{ Antigen frequencies (\%) } & \multirow{2}{*}{$\begin{array}{l}\text { Odds } \\
\text { ratio }\end{array}$} & \multirow[t]{2}{*}{$\chi_{1}^{2}$} \\
\hline & & patients & controls & patients & controls & & \\
\hline $\begin{array}{l}\text { B8 positive } \\
\text { B8 negative }\end{array}$ & DR3 & $\begin{array}{l}36 \\
57\end{array}$ & $\begin{array}{r}70 \\
191\end{array}$ & $\begin{array}{l}97 \\
26\end{array}$ & $\begin{array}{r}83 \\
9\end{array}$ & $\begin{array}{l}7.2 \\
3.4\end{array}$ & $\begin{array}{r}4.6 \\
10.9\end{array}$ \\
\hline $\begin{array}{l}\text { DR3 positive } \\
\text { DR3 negative }\end{array}$ & B8 & $\begin{array}{l}50 \\
43\end{array}$ & $\begin{array}{r}76 \\
185\end{array}$ & $\begin{array}{r}70 \\
2\end{array}$ & $\begin{array}{r}76 \\
7\end{array}$ & $\begin{array}{l}0.7 \\
0.3\end{array}$ & $\begin{array}{l}0.6 \\
1.1\end{array}$ \\
\hline $\begin{array}{l}\text { Dw4 positive } \\
\text { Dw4 negative }\end{array}$ & DR4 & $\begin{array}{l}50 \\
38\end{array}$ & $\begin{array}{l}26 \\
87\end{array}$ & $\begin{array}{r}100 \\
37\end{array}$ & $\begin{array}{l}89 \\
12\end{array}$ & $\begin{array}{l}\text { N.D. } \\
4.5\end{array}$ & $\begin{array}{r}6.0 \\
11.0\end{array}$ \\
\hline $\begin{array}{l}\text { DR4 positive } \\
\text { DR4 negative }\end{array}$ & Dw4 & $\begin{array}{l}64 \\
24\end{array}$ & $\begin{array}{l}33 \\
80\end{array}$ & $\begin{array}{r}78 \\
0\end{array}$ & $\begin{array}{r}70 \\
4\end{array}$ & $\begin{array}{l}1.6 \\
0\end{array}$ & $\begin{array}{l}0.8 \\
0.9\end{array}$ \\
\hline
\end{tabular}

The frequencies of selected HLA-B, D, and -DR antigens were investigated in various subgroups of IDD patients and in corresponding groups of controls. For example, line 1 shows that the frequency of DR3 in 36 B8-positive patients was $97 \%$, and the frequency of DR3 in 70 B8-positive controls was $83 \%$. This gives an odds ratio of 7.2 and a $\chi_{1}^{2}$ d.f. of 4.6 for significance. Accordingly, the frequency of DR3 is significantly increased in B8-positive patients compared with B8-positive controls. Similarly, DR3 is also increased in B8-negative patients compared with B8-negative controls. In contrast, B8 is not increased in DR3-positive or -negative patients compared with the corresponding groups of controls

N.D. $=$ not defined

showed the closest association with IDD, we compared the frequency of DR3 in B8-positive and B8negative patients and controls. Table 2 gives an example of the analysis. It appears that DR3 was significantly increased in both B8-positive and B8negative patients, whereas $B 8$ was increased neither in DR3-positive nor in DR3-negative patients. The same analysis was performed for $B 8$ versus $D w 3$, $\mathrm{B} 15$ versus D/DR4, B18 versus D/DR3 and D/DR4 and $B 7$ versus $D / D R 2$ (data not shown). In all cases the HLA-D/DR antigens showed the strongest association. The same analysis was performed for HLA-Dw4 versus DR4 (see below).

\section{$H L A-D$ Versus $H L A-D R$}

Table 3 shows the $2 \times 2$ tables for comparison of the HLA-D and -DR antigens. In general there was good correlation between HLA-D and -DR for all antigens except for Dw4/DR4 where DR-typing gives a much broader definition of the "D/DR4" antigen than does D-typing. Fourteen $(15.9 \%)$ of the patients were negative with the MLC technique (HLA-D) but were detected by the serological technique (HLA-DR), and DR4 was significantly increased in both Dw4-positive and negative patients (Table 2). It appears from Table 4 that approximately half of the patients and control subjects who are both Dw4 and DR4 positive also carry the B15antigen, whereas only one of the 14 patients and none of the 10 controls positive for DR4 and negative for Dw4 were B15 positive. Eight of the DR4positive/Dw4 negative patients were typed for HLAD/DR associated PLT-defined DP-antigens and six of these patients were DP4-positive while two patients were DP4-negative. 
Table 3. Results of HLA-D versus HLA-DR typing in IDD patients

\begin{tabular}{lrlrlll}
\hline $\begin{array}{l}\text { HLA-D/DR } \\
\text { specificity }\end{array}$ & $+/+$ & $+1-$ & $-1+$ & $-1-$ & $\mathrm{n}$ & $\mathrm{r}$ \\
\hline 1 & 11 & 4 & 1 & 70 & 86 & 0.79 \\
2 & 3 & 0 & 0 & 86 & 89 & 1.0 \\
3 & 45 & 3 & 4 & 37 & 89 & 0.84 \\
4 & 50 & 0 & 14 & 24 & 88 & 0.70 \\
$5^{\text {a }}$ & 3 & 1 & 1 & 57 & 62 & 0.73 \\
7 & 5 & 0 & 0 & 84 & 89 & 1.0 \\
8 & 6 & 0 & 2 & 81 & 89 & 0.86 \\
\hline
\end{tabular}

Entries are numbers of patients

$+1+=$ positive for both HLA-D and HLA-DR

$+1-=$ positive for HLA-D and negative for HLA-DR

$-1+=$ negative for HLA-D and positive for HLA-DR

$-1-=$ negative for both HLA-D and HLA-DR

$\mathrm{n} \quad=$ total number of patients studied for both of the corresponding antigens

$\mathrm{r} \quad=$ correlation coefficient

a HLA-DR5 has been determined only in the Funen series

\section{HLA-D/DR Antigen Frequencies}

Table 5 shows the HLA-D and -DR frequencies in the different patient groups, in all patients combined, and in controls. A very consistent pattern can be seen: HLA-D/DR3 and D/DR4 were all increased in all groups and D/DR2 and D/DR7 were decreased. DR4 was especially increased in the Funen series $(77.3 \%)$ but the difference between this and the other groups was not significant $(p=0.07)$. Dw2 was found only in three of 164 patients $(1.8 \%)$ compared with $27.5 \%$ of the control subjects; all three were also DR2-positive and the two investigated patients were both DP2-positive. Twenty-five of the 164 patients were B7-positive.

\section{Familial Versus Isolated Cases}

The HLA-D and -DR frequencies for both familial and isolated cases are given in Table 5. Only minor and insignificant differences between the different groups were found. Due to methods of ascertainment only the isolated cases from the Funen series can be regarded as "truly" isolated: a number of the cases from the prospective series may later become familial.

\section{HLA-D and -DR Phenotype Distribution}

Table 6 gives selected HLA-D and -DR phenotypes in patients and in controls. It appears that the relative risk in 3,4 heterozygotes by far exceeds the risk for the D/DR3 and 4 "homozygotes", which again show higher relative risk than the D/DR3 and 4 heterozy- gotes, respectively. It should, however, be noted that the D/DR3 and 4 phenotypes may comprise both the true homozygotes $(D / D R 3 / 3$ and $D / D R 4 / 4)$ and heterozygotes $D / D R 3 / O$ and $D / D R 4 / O$ (where " 0 " indicates as yet unknown D/DR genes, i. e. a "blank" or "null").

It is worth noting that $86.7 \%$ and $93.4 \%$ of all the patients have either Dw3 or Dw4 and either DR3 or DR4, respectively, compared with $50.8 \%$ and $57.3 \%$ in the control group. An individual who is DR3 and/ or DR4 positive has an eight times higher risk of developing IDD than individuals lacking both these antigens.

\section{Age at Onset and Phenotypes}

The patients were grouped according to whether age at onset was below or above 15 years (data not shown). When comparing the phenotype distribution in the two age groups by $2 \times 6$ tables, the $\chi^{2}$ value does not reach significance for HLA-D, nor for -DR $\left(\chi_{5}^{2}=5.4\right.$ and 9.5 , respectively).

\section{Sibling Pair Analysis}

The numbers of sibling pairs sharing two, one or zero haplotypes are given in Table 7 for the two series; three sibling pairs from the prospective series have been added to the sibling pair series. Two pairs sharing no haplotypes were found and these were further investigated in the families but found to fit the segregation pattern. The figures are too small to allow testing of different genetic models (see Discussion) and we have therefore added previously published data together with those obtained in the 8th International Histocompatibility Workshop. The proportions of shared haplotypes in the different groups are very similar in the two series.

The distribution of the three classes of sibling pairs was analyzed for the total data set and the results are shown in Fig. 1. It appears that the minimum $\chi^{2}$ for the dominant model is unacceptably high at $16.9(\mathrm{p}<0.001)$. For the recessive model the lowest and highest acceptable frequencies of the "diabetes gene" are 0.234 and $0.383\left(\chi_{2}^{2}\right.$-value of $5.99 \sim \mathrm{p}=0.05)$. The minimum $\chi^{2}$ of 0.45 is found at the gene frequency of 0.300 .

\section{Discussion}

For some time it has been a matter of discussion [38] how to test which HLA factor is most strongly associated with a disease when HLA antigens from more than one series show association. This difficulty arises from the well-known linkage disequilibrium between the HLA-A,B,C and D/DR loci. 
Table 4. Correlation between HLA-B15 and Dw4 in DR4-positive patients and control subjects

\begin{tabular}{|c|c|c|c|c|c|}
\hline & & & $\begin{array}{l}\text { HLA-B15 } \\
\text { positive }\end{array}$ & $\begin{array}{l}\text { HLA-B15 } \\
\text { negative }\end{array}$ & p (Fisher) \\
\hline $\begin{array}{l}\mathrm{IDD} \\
\mathrm{n}=88\end{array}$ & $\begin{array}{l}\text { HLA-DR4 positive } \\
\mathrm{n}=64\end{array}$ & $\begin{array}{l}\text { Dw4 positive } \\
\mathrm{n}=50 \\
\text { Dw4 negative } \\
\mathrm{n}=14\end{array}$ & 26 & 24 & $\mathrm{p}=2.1 \times 10^{-3}$ \\
\hline $\begin{array}{l}\text { Controls } \\
\mathrm{n}=113\end{array}$ & $\begin{array}{l}\text { HLA-DR } 4 \text { positive } \\
\mathrm{n}=\mathbf{3 3}\end{array}$ & $\begin{array}{l}\text { Dw4 positive } \\
\mathrm{n}=23\end{array}$ & 11 & 12 & $p=7.0 \times 10^{-3}$ \\
\hline
\end{tabular}

Entries are numbers of individuals

Table 5. HLA-D and -DR frequencies (\%) in different groups of IDD patients and in control subjects

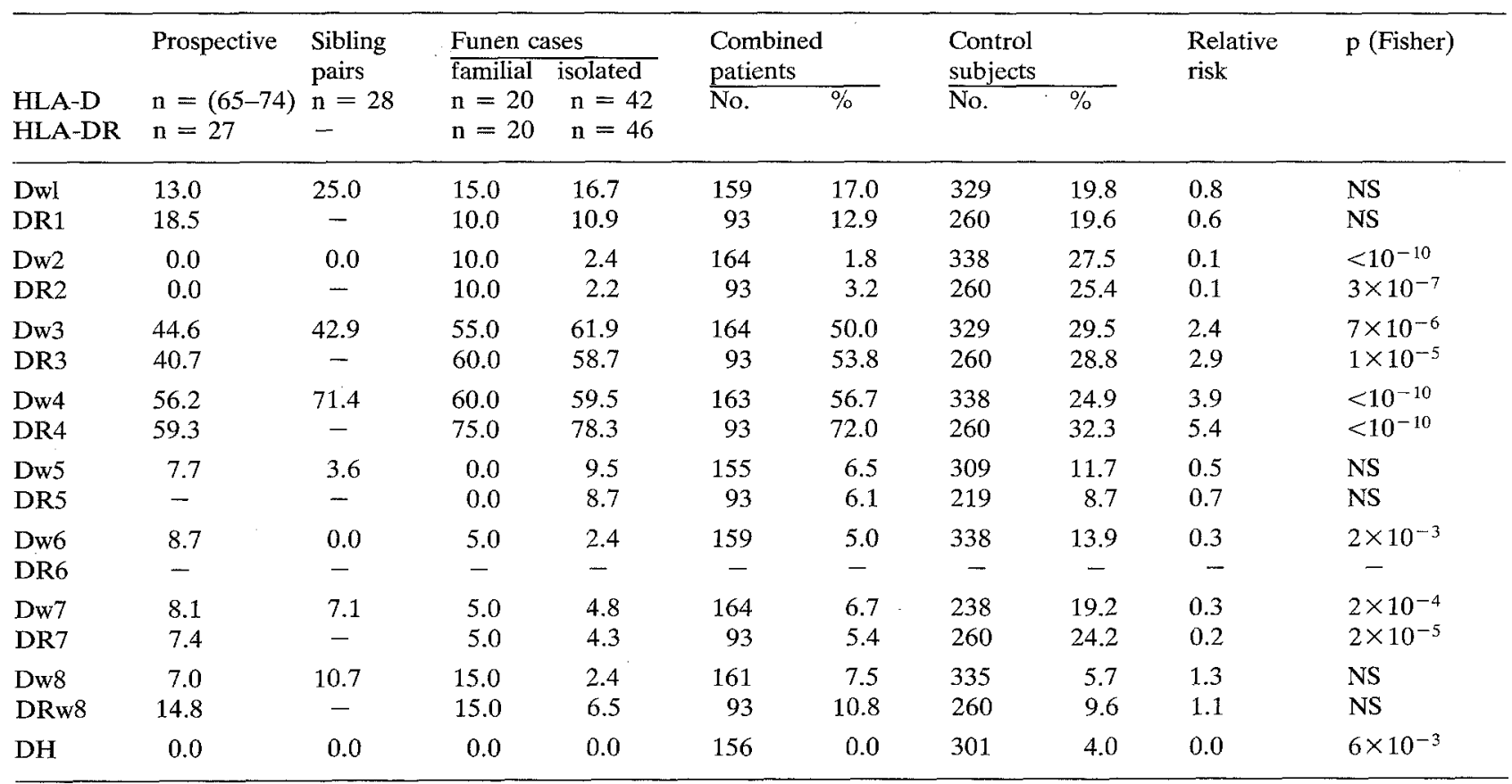

p-values concern the comparisons of antigen frequencies between combined patients and control subjects

$\mathrm{NS}=$ not significant; $-=$ not tested

However, a simple procedure of stratification is possible which may distinguish between primary and secondary associations [13]. The frequency of various HLA-D/DR antigens is investigated in subsets of patients and controls with and without a certain HLA-B antigen and vice versa as exemplified in Table 2. For $\mathrm{B} 8$ and $\mathrm{D} / \mathrm{DR} 3, \mathrm{~B} 15$ and $\mathrm{D} / \mathrm{DR} 4$, and for $\mathrm{B} 7$ and $\mathrm{D} / \mathrm{DR} 2$ it is clear that the strongest associations are with the HLA-D/DR antigens. The same conclusion was reached by Sachs et al. [25] using a different approach. The picture for B18 versus $\mathrm{D} / \mathrm{DR} 3$ and $\mathrm{D} / \mathrm{DR} 4$ is less clear in our study where $\mathrm{B} 18$ seems to be associated with both D/DR3 and D/DR4. However, de Mouzon et al. [18] have clearly shown that B18 is associated with DR3 in Basque IDD patients and controls and that DR3 is more strongly associated with IDD than is B18.

The gene(s) controlling these hypothetical factors must be closer to the HLA-D/DR than to the HLAB locus. Nevertheless, it is possible that the $H L A-D /$ $D R 3$ and $D / D R 4$ genes themselves control the susceptibility to IDD. It cannot be excluded that some D/DR3 or D/DR4 carrying haplotypes may be more strongly associated with IDD than others, but this 
Table 6. Frequencies (\%) of selected HLA-D and -DR phenotypes and relative risks for these phenotypes

\begin{tabular}{|c|c|c|c|c|}
\hline \multirow{3}{*}{\multicolumn{2}{|c|}{ Phenotype }} & \multirow{3}{*}{$\begin{array}{l}\text { Combined } \\
\text { patients } \\
\text { Dw } n=151 \\
\text { DR } n=93\end{array}$} & \multirow{3}{*}{$\begin{array}{l}\text { Control sub- } \\
\text { jects } \\
\text { Dw } n=293 \\
\text { DR } \quad n=260\end{array}$} & \multirow[t]{3}{*}{ Relative risk } \\
\hline & & & & \\
\hline & & & & \\
\hline Dw & \multirow{2}{*}{$3, \mathrm{X}$} & 11.9 & 15.7 & 2.8 \\
\hline $\mathrm{DR}$ & & 9.7 & 12.7 & 2.9 \\
\hline Dw & \multirow{2}{*}{3} & 13.9 & 9.2 & 5.6 \\
\hline $\mathrm{DR}$ & & 9.7 & 12.3 & 4.3 \\
\hline $\mathrm{Dw}$ & \multirow{2}{*}{3,4} & 25.2 & 4.4 & 21.2 \\
\hline DR & & 34.4 & 3.8 & 44.4 \\
\hline Dw & \multirow{2}{*}{4} & 18.5 & 6.8 & 10.1 \\
\hline DR & & 22.6 & 11.2 & 10.5 \\
\hline Dw & \multirow{2}{*}{$4, X$} & 17.2 & 14.7 & 4.3 \\
\hline DR & & 15.1 & 17.3 & 4.3 \\
\hline Dw & \multirow{2}{*}{$\mathrm{X}, \mathrm{X}$} & 13.3 & 49.2 & $(1.0)$ \\
\hline DR & & 8.6 & 42.6 & $(1.0)$ \\
\hline
\end{tabular}

The relative risks were calculated for the combined patient group using the " $X, X$ " phenotype as reference. In the HLA-Dw3. $X$ and $4, X$ phenotypes ' $X$ ' indicates the presence of an additional HLAD antigen (HLA-Dw1,2,5,6,7, or 8). In the HLA-DR3, X and 4,X phenotypes ' $\mathrm{X}$ ' indicates the presence of an additional HLA-DR antigen (HLA-DR1,2,5,7, or w8). The $X, X$ phenotype includes all individuals lacking $\mathrm{D}, \mathrm{DR} 3$ or $\mathrm{D}, \mathrm{DR} 4$. The phenotype distributions did not differ significantly from Hardy-Weinberg expectations in patients or control subjects, but there was an excess of Dw3,4 patients (observed: 38 , expected: 31.5 ; the corresponding figures for control subjects were 13 and 12.9 , respectively) and an excess of DR3,4 patients (observed: 32 , expected: 26.2 ; the corresponding figures for control subjects were 10 and 14.6 , respectively)

Table 7. HLA haplotype sharing among affected sibling pairs

\begin{tabular}{lccccc}
\hline No. shared haplotypes: & & 2 & 1 & 0 & $\mathrm{n}$ \\
\hline No. of sibling pairs & & & & & \\
Sibling pairs series & & 16 & 13 & 2 & 31 \\
Funen series & & 11 & 9 & 0 & 20 \\
Total Danish series: & $\mathrm{n}=$ & 27 & 22 & 2 & 51 \\
& $\%=$ & 52.9 & 43.1 & 3.9 & \\
Other data including & & & & & \\
8th Workshop data & $\mathrm{n}=$ & 127 & 75 & 10 & 212 \\
and published data ${ }^{\mathrm{a}}$ & $\%=$ & 59.9 & 35.4 & 4.7 & \\
& $\mathrm{n}=$ & 154 & 97 & 12 & 263 \\
Total & $\%=$ & 58.6 & 36.9 & 4.6 & \\
& $\%$ &
\end{tabular}

a From [1, 6, 24, 28, 29] and Møller and Persson, personal communication (eight pairs)

does not seem likely on the basis of this analysis. From recent histocompatibility workshops $[11,12]$ it is obvious that HLA-D and -DR antigens are closely related, but it is still uncertain whether the HLA-D and -DR antigens are the same or different antigenic determinants on the same molecule, or whether they

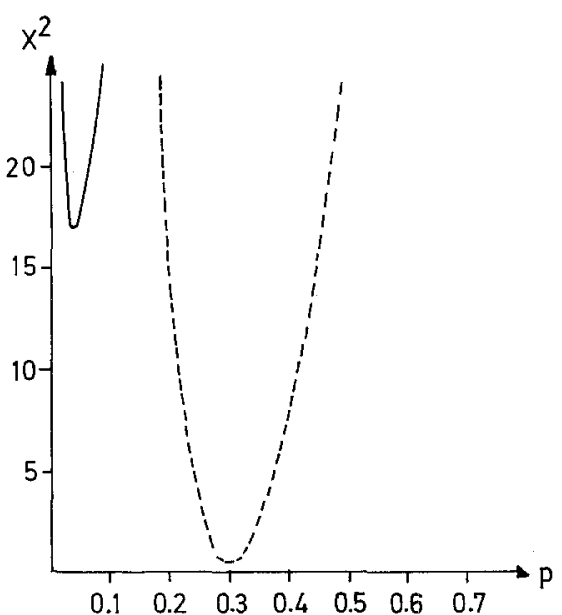

Fig. 1. The abscissa is the frequency of the putative "diabetes gene", and the ordinate is the chi square ( 2 d.f.) for the goodness of fit between the observed distribution and those expected for a dominant (full line) and a recessive model (broken line)

are controlled by different but closely linked genes. It is interesting from both genetic and biological points of view that IDD is associated not only with the Dw4 but also with the "Dw4-/DR4" antigen. Thus, for practical purposes, DR-typing seems at the moment to be the method of choice in further studies in IDD. The existence of HLA-Dw4 negative/DR4 positive individuals as a separate entity has been noted earlier in healthy individuals [15] and is substantiated by the observation that this phenotype is not associated with HLA-B15 as is the Dw4 positive/DR4 positive phenotype.

The D/DR2 antigen has earlier been noted to be absent or of very low frequency in IDD [30] and this was confirmed in this study. The fact that all DR2 positive propositi were either DR3 or DR4 positive is worth noting because it argues against the assumption that IDD in these patients represents geno- or phenocopies.

One of the purposes of the study design of the Funen series was to look for possible differences in the HLA-D/DR antigen frequencies between familial and isolated cases because the results from the prospective and the sibling pair series had suggested such differences [30]. To investigate this problem we selected all affected sibling pairs in the Funen series and compared them with a group of patients with no affected first degree family member and with at least two healthy siblings aged 20 years or more. When comparing these two groups, the antigen and phenotype distributions were almost identical. One reason for this discrepancy with our previous findings $[30,36]$ might be that in the prospective series we ascertained patients with age at onset up to 30 years while the Funen series had age at onset before 20 
years. Nevertheless, it is striking that the HLA-D/ DR frequencies and phenotype distributions in familial and isolated cases are so similar, which indicates that the genetic component in the familial and isolated cases are at least to some extent the same, and that HLA related genes play the major role in the predisposition to IDD in both cases. Bengsch et al. [2] investigated HLA-A,B antigens in both familial and isolated cases and found similar antigen frequencies in both groups in accordance with the above conclusion.

On the basis of an increased risk for $H L A-B 8 /$ $B 15$ heterozygotes compared with both $B 8 / 8$ and $B 15 / 15$ homozygotes, we suggested an overdominant or epistatic model involving two different HLA genes conferring susceptibility to IDD [29]. This assumption was also supported by the observation that $\mathrm{B} 8$ and not B15 is common for a variety of organ specific autoimmune diseases [35]. More recently, other investigators have proposed both recessive [22] and dominant [27] models for the HLA controlled susceptibility to IDD. As discussed by Day and Simons [8], HLA data on affected sibling pairs may allow distinction between the dominant and recessive models.

The analysis in Fig. 1 of HLA haplotype sharing among affected sibling pairs shows clearly that a dominant model (with or without incomplete penetrance) can now be ruled out. The recessive model (with or without incomplete penetrance) cannot be excluded, but the lowest gene frequency for the putative susceptibility gene compatible with the observations is so high (0.234) that the frequency of homozygotes (i.e. susceptible) in the population would be $(0.234)^{2}=0.055$. Because the frequency of IDD in the population is 0.003 [10] this would imply a penetrance of $0.003 / 0.005=0.055$ or $5.5 \%$. This figures seems unacceptably low both when compared with either the concordance rates in monozygotic twins or the frequency (0.06) of IDD in siblings of IDD propositi [9]. Only a fraction of such siblings will be homozygous for the susceptibility gene and thus the average frequency of IDD in siblings or IDD propositi should be lower than the penetrance for homozygotes. Accordingly, we also consider the recessive model unlikely.

Most recently, Spielman et al. [28] have suggested that the susceptibility to IDD may be intermediate between a dominant and a recessive trait. This model is attractive in several ways. Firstly, it is not incompatible with the observations of HLA-sharing in sibling pairs. Secondly, it can be tested on the basis of population data. However, it can be shown that an intermediate model cannot lead to an excess of $D R 3 / 4$ heterozygotes when tested for HardyWeinberg equilibrium, (Ryder unpublished data) and that the risk for these heterozygotes cannot be higher than those for both $D R 3 / 3$ and $4 / 4$ homozygotes [39]. In fact, the highest risk in Table 6 concerns $D / D R 3 / 4$ heterozygotes. However, a major problem here is the uncertainty of the homo/heterozygosity of the individuals having only DR3 or DR4, which makes it impossible to establish from these data whether the risk for $D / D R 3 / 4$ heterozygotes is indeed the highest of all risks. Accordingly, this analysis has not ruled out the possibility of an intermediate model. If there are two IDD-susceptibility genes in HLA, the analysis in Table 6 indicates that both of these may have a dose effect (i. e. have intermediate action) because the relative risks for the $\mathrm{D} / \mathrm{DR} 3, \mathrm{X}$ and $\mathrm{D} / \mathrm{DR} 4, \mathrm{X}$ phenotypes are considerably lower than those for the D/DR3 and D/DR4 phenotypes.

It would be crucial evidence against the intermediate model if it could be shown that certain clinical or laboratory variables are associated either with DR3 or DR4 in IDD. Using age at onset as criterion, we failed to find such heterogeneity.

It is possible to give some crude empirical estimates of the chance of developing IDD for various classes of siblings of IDD patients independently of the models of inheritance. Degnbol and Green [9] found that the cumulative incidence ratio of diabetes for siblings of IDD patients before age 20 years is $5.1 \%$, and it can be seen from Table 7 that $58.6 \%$ of all affected sibling pairs are HLA identical. Thus, $0.586 \times 0.051=0.030(3 \%)$ of siblings will be both HLA identical with the affected propositus and develop diabetes before age 20 years. Because $25 \%$ of all siblings are HLA identical with the propositus, it appears that $0.03 / 0.25=0.12$, i. e. $12 \%$ of siblings who are HLA identical with the propositus will develop diabetes before age 20 years and $4 \%$ and $1 \%$ for siblings who share one or no haplotypes with the propositus, respectively.

Acknowledgements. We wish to thank all the patients and their relatives for their willingness to cooperate in these studies, as well as the medical staff of all the departments making the prospective study possible. Mrs. C. Dam-Sørensen typed the manuscript and we are indebted for many helpful discussions with doctor Niels Holm. These studies were supported by grants from the Danish Medical Research Council, the Danish Diabetic Association, the Nordisk Insulin Foundation and the Dagmar Marshall Foundation.

Note. A list with detailed data on all patients is available from the authors on request.

\section{References}

1. Barbosa J, King R, Noreen H, Yunis EJ (1977) The histocompatibility system in juvenile insulin-dependent diabetic multiple kindreds. J Clin Invest 60: 989-998 
2. Bengsch N, Köbberling J, Eckert G, Willms B (1978) HLAtyping in juvenile diabetics with and without positive family history and in families with one and two diabetic siblings. Diabetologia 15: 447-451

3. Cavalli-Sforza LL, Bodmer WF (1971) In: The genetics of human populations. WH Freeman and Company, San Francisco, p 45-62

4. Christau B, Kromann H, Christy M, Andersen OO, Nerup J (1979) Incidence of insulin-dependent diabetes mellitus (0-29 years at onset) in Denmark. Acta Med Scand [Suppl] 624: $54-60$

5. Christy M, Green A, Christau B, Kromann H, Nerup J, Platz P, Thomsen M, Ryder LP, Svejgaard A (1979) Studies of the HLA system and insulin-dependent diabetes mellitus. Diabetes Care 2: 209-214

6. Cudworth AG (1978) Type I diabetes mellitus. Diabetologia 14: $281-291$

7. Cudworth AG, Festenstein H (1978) HLA genetic heterogeneity in diabetes mellitus. $\mathrm{Br}$ Med Bull 34: 285-289

8. Day NE, Simons MJ (1976) Disease susceptibility genes their identification by multiple case family studies. Tissue Antigens 8: 109-119

9. Degnbol B, Green A (1978) Diabetes mellitus among first and second degree relatives of early onset diabetics. Ann Hum Genet 42: 25-47

10. Green A, Hauge M, Holm NV, Rasch LL (1981) Epidemiological studies of diabetes mellitus in Denmark: II. A prevalence study based on insulin prescriptions. Diabetologia 20: $468-470$

11. Histocompatibility Testing 1977 (1978) In: Bodmer WF, Batchelor JR, Bodmer JG, Festenstein H, Morris PJ (eds) Histocompatibility testing. Munksgaard, Copenhagen, p 1-612

12. Histocompatibility Testing 1980 (1980) In: Terasaki PI (ed) Histocompatibility testing UCLA, Los Angeles, California

13. Keuning JJ, Peña AS, van Hooff JP, van Leeuwen A, van Rood JJ (1976) HLA-Dw3 associated with coeliac disease. Lancet I: 506

14. Kissmeyer-Nielsen F, Kjerbye KE (1967) Lymphocytotoxic microtechnique. Purification of lymphocytes by flotation. In: Curtoni ES, Mattiuz PL, Tosi RM (eds) Histocompatibility testing. Munksgaard, Copenhagen, p 381-383

15. Lamm LU, Kristensen T, Jørgensen F, Kissmeyer-Nielsen $F$ (1977) Serological and cellular HLA-determinants - A panel study. Tissue Antigens 10: 138

16. Morling N, Jakobsen BK, Platz P, Ryder LP, Svejgaard A, Thomsen M (1980) Typing for HLA-D/DR associated DPantigens with the primed lymphocyte typing (PLT) technique. Tissue Antigens 15: 471-482

17. Morling N, Jakobsen BK, Platz P, Ryder LP, Svejgaard A, Thomsen M (1981) Correlations between HLA-D/DR associated primed lymphocyte typing (PLT) defined DP-antigens, HLA-D and HLA-DR antigens. Tissue Antigens (in press)

18. Mouzon A de, Ohayon E, Ducos J, Hauptmann G (1979) Bf and $\mathrm{C} 4$ markers for insulin-dependent diabetes in Basques. Lancet II: 1364

19. National Diabetes Data Group (1979) Classification and diagnosis of diabetes mellitus and other categories of glucose intolerance. Diabetes 28: 1039-1057

20. Nerup J, Platz P, Andersen OO, Christy M, Lyngsøe J, Poulsen JE, Ryder LP, Nielsen LS, Thomsen M, Svejgaard A (1974) HL-A antigens and diabetes mellitus. Lancet II: 864-866

21. Nerup J, Platz P, Ryder LP, Thomsen M, Svejgaard A (1978) HLA, islet cell antibodies, and types of diabetes mellitus. Diabetes 27: 247-250

22. Rubinstein P, Suciu-Foca N, Nicholson JF (1977) Genetics of juvenile diabetes mellitus. N. Engl J Med 297: 1036-1040
23. Ryder LP, Andersen E, Svejgaard A (1979) HLA and disease registry. Third report. Munksgaard, Copenhagen

24. Ryder LP, Christy M, Nerup J, Platz P, Svejgaard A, Thomsen M (1979) HLA studies in diabetics. In: Camerini-Davalos RA, Hanover B (eds) Treatment of early diabetes. Plenum Press, New York, p 41-48

25. Sachs JA, Cudworth AG, Jaraquemada D, Gorsuch AN, Festenstein $H$ (1980) Type I diabetes and the HLA-D locus. Diabetologia 18: 41-43

26. Singal DP, Blajchman MA (1973) Histocompatibility (HL-A) antigens, lymphocytotoxic antibodies and tissue antibodies in patients with diabetes mellitus. Diabetes 22: 429-432

27. Spielman RS, Baker L, Zmijewski CM (1979) Inheritance of susceptibility to juvenile onset diabetes. In: Sing CF, Skolnick $M$ (eds) Genetic analysis of common diseases: Applications to predictive factors in coronary disease. Liss, New York, $p$ $567-585$

28. Spielman RS, Baker L, Zmijewski CM (1981) Gene dosage and susceptibility to insulin-dependent diabetes. Ann Hum Genet 44: 135-150

29. Svejgaard A, Platz P, Ryder LP, Nielsen LS, Thomsen M (1975) HL-A and disease associations - A survey. Transplant Rev 22: 3-43

30. Svejgaard A, Christy M, Nerup J, Platz P, Ryder LP, Thomsen $M$ (1978) HLA and autoimmune disease with special reference to the genetics of insulin-dependent diabetes. In: Rose NR, Bigazzi PE, Warner NL (eds) Genetic control of autoimmune disease. Elsevier, North Holland, New York, p 101-112

31. Svejgaard A, Hauge M, Jersild C, Platz P, Ryder LP, Staub Nielsen L, Thomsen M (1979) The HLA system. An introductory survey. In: Beckman L, Hauge M (eds) Monographs in human genetics. Karger, Basel

32. Svejgaard A, Platz P, Ryder LP (1980) Insulin-dependent diabetes mellitus. In: Terasaki PI (ed) Histocompatibility testing 1980. UCLA, Los Angeles, California, p 638-656

33. Thomsen M, Hansen GS, Svejgaard A, Jersild C, Hansen JA, Good RA, Dupont B (1974) Mixed lymphocyte culture technique. Tissue Antigens 4: 495-506

34. Thomsen M, Jakobsen BK, Platz P, Ryder LP, Staub Nielsen L, Svejgaard A (1975) LD-typing, polymorphism of MLC determinants. In: Kissmeyer-Nielsen F (ed) Histocompatibility testing 1975. Munksgaard, Copenhagen, p 509-518

35. Thomsen M, Platz P, Andersen OO, Christy M, Lyngsøe J, Nerup J, Rasmussen K, Ryder LP, Staub Nielsen L, Svejgaard A (1975) MLC typing in juvenile diabetes mellitus and idiopathic Addison's disease. Transplant Rev 22: 125-147

36. Thomsen M, Nerup J, Christy M, Andersen OO, Kromann H, Platz P, Ryder LP, Svejgaard A (1980) HLA antigens and diabetes. In: Burman D, Holton JB, Pennock CA (eds) Inherited disorders of carbohydrate metabolism. MTP Press, Lancaster, p 401-409

37. Thomson G, Bodmer WF (1977) The genetics of HLA and disease association. In: Barndorff-Nielsen $O$, Christiansen $F B$, Fenchel $\mathrm{T}$ (eds) Measuring selection in natural populations. Munksgaard, Copenhagen, pp 545-563

38. Thomson G, Bodmer WF (1979) HLA haplotype associations with disease. Tissue Antigens 13: 91-102

39. Svejgaard A, Ryder LP (1981) HLA genotype distribution and genetic models of insulin-dependent diabetes mellitus. Ann Hum Genet (in press)

Received in revised form: 16 February 1981

Dr. P. Platz

Tissue Typing Laboratory

University Hospital (Rigshospitalet)

Blegdamsvej 9

DK-2100 Copenhagen $\varnothing$

Denmark 